\title{
Postharvest responses of carnation cut flowers to Prunus cerasoides mediated silver nanoparticle
}

\author{
Le Thi Anh Tu*
}

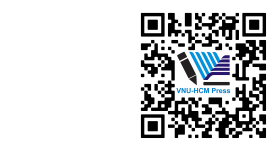

Use your smartphone to scan this QR code and download this article

Dalat University, Dalat, Vietnam

\section{Correspondence}

Le Thi Anh Tu, Dalat University, Dalat, Vietnam

Email: tulta@dlu.edu.vn

\section{History}

- Received: 2020-10-26

- Accepted: 2020-12-28

- Published: 2020-12-31

DOI : 10.32508/stdj.v23i4.2478

\section{Check for updates}

\section{Copyright}

(c) VNU-HCM Press. This is an openaccess article distributed under the terms of the Creative Commons Attribution 4.0 International license.

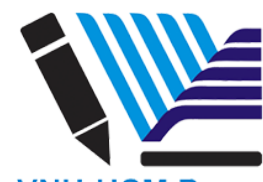

VNU-HCM Press

\begin{abstract}
Introduction: The procedure to synthesize silver nanoparticles (SNPs) from Prunus cerasoides leaf extract and their effect on vase life and flower quality of cut carnation were investigated. Methods: SNPs were bio-synthesized from Prunus cerasoides leaf extract and characterized by using UVVis technique, TEM, and SEM images. The postharvest responses of carnation cut flowers to the biosynthesis SNPs were evaluated through vase life, relative fresh weight, vase solution uptake, flower diameter of cut carnation. Results: SNPs were synthesized under optimum conditions, including using the extract of leaf heating at $60^{\circ} \mathrm{C}$ in $30 \mathrm{~min}, 4 \mathrm{mM}$ of silver nitrate, $\mathrm{pH}$ of 11, and 180 min of reaction time. SNPs exhibited antimicrobial activity and then alleviated the bacterial development in the preservative solution. All treatments with SNPs had improved the vase life and quality of cut carnation compared to the control. A vase solution containing $2 \%$ sucrose enhanced the carnation cut flowers. Conclusions: The preservative solution containing 25 ppm SNPs and $2 \%$ sucrose showed the best effect. SNPs could be used as a promising antibacterial agent applied in the preservative solution for cut carnation flowers.
\end{abstract}

Key words: antibacterial, leaf extract, Prunus cerasoides, silver nanoparticles

\section{INTRODUCTION}

Carnation (Dianthus caryophyllus L.) is one of the popular ornamental crops in the world ${ }^{1}$. Carnation has long been sold as cut flowers owning the excellent quality, a wide range of colors, forms, ability to withstand long-distance transportation and rehydrate after continuous shipping ${ }^{2}$. The short vase life and wilting are the main problems of cut flowers. The vase life of carnation is under the influence of the synthesis of ethylene and vascular blockage ${ }^{3}$. Stem end blockage causes the imbalance between water uptake and water loss, therefore affects the longevity of cut flowers ${ }^{4}$. Microbial contaminations at the stem end and in the vase solution associated with the xylem blockage of carnation, and then abbreviated the vase life ${ }^{5}$.

In recent years, metal nanoparticles have long been recognized in diverse applications in various industries such as health, environment, energy, chemistry, agriculture, food industry, and cosmetics ${ }^{6}$. Among metal nanoparticles, silver nanoparticles (SNPs) are the most commonly studied for biosystems ${ }^{7}$. SNPs have a high surface area and a high fraction of surface atoms as compared to the bulk silver. They are stable and well dispersed in aqueous solutions. Their high surface area to volume ratio leads to good contact with microorganism ${ }^{8}$. SNPs attach to the cell and disrupt the outer membrane of target cells or penetrate into the bacterial cells and alter cellular respiration and cell division ${ }^{9}$.

Many methods have been used for SNPs synthesis, including physical method such as attrition and pyrolysis, chemical reduction, or photochemical reduction. Contamination, energy consumption, or high expense are the drawbacks of the above methods ${ }^{10}$. Currently, SNPs can be bio-synthesized by microorganisms, enzymes, fungi, and plant ${ }^{11-14}$. Biosynthesis of SNPs by using plants is advantageous over other biological processes in terms of environmental favorable, less time consuming, large-scaled up, low cost, and elaborate processes of maintaining microbial cultures ${ }^{15}$. Plants have flavonoids, alkaloids, and polyphenolic compounds, which play a role in reducing or stabilizing agents ${ }^{16}$.

Prunus cerasoides is a deciduous tree of the family Rosaceae. The tree has a wide range of uses in edible fruit, seed, and gum, various medicinal applications, timber, dye-stuff, tannins, and beads ${ }^{17}$. Phytoconstituents from the extract of plants consist of flavonoids, terpenoids, glycosides, alkaloids, saponins, phenolics, and tanins ${ }^{18}$. Leaf extract of $P$ runus cerasoides contains three different fractions of methanolic that are used against prostate and urine disorder ${ }^{17}$. This study was designed to investigate the green synthesis of SNPs using Prunus cerasoides leaf extract and their potential in preserving cut carnation 
in order to suggest a promising method in prolonging the vase life and enhancing the quality of carnation cut flowers.

\section{MATERIALS AND METHODS MATERIALS}

The healthy Prunus cerasoides leaves were collected in Dalat, Lamdong, Vietnam. The leaves were washed 3 times with tap water and twice with sterile water, dried up, and finally ground for synthesis SNPs. The voucher specimen is available from the resource unit Herbarium of Dalat University, Lamdong, Vietnam. Silver nitrate was obtained from Merck, Germany. Carnation (Dianthus caryophyllus L.) were purchased from a local greenhouse at their optimum developmental stage with the uniformity size, color, and lack of defects. Flowers were placed immediately in a sterile water bucket, covered with a plastic film, and transported to the laboratory. Stems were re-trimmed to a length of $20 \mathrm{~cm}$ (under de-ionized water). The experiments were carried out at the same day.

\section{Synthesis of SNPs}

$15 \mathrm{~g}$ of ground leaves were placed in $200 \mathrm{ml}$ of distilled water and then boiled for $60 \mathrm{oC}$ with continuous stirring at the heating duration of $5,10,15,20,25$, and $30 \mathrm{~min}$. The mixture was cooled down and then filtered with the Whatman paper number 1 . The filtrate was collected. The varying initial concentrations of AgNO3 (1, 2, 3, $4 \mathrm{mM}$ ) were prepared in distilled water. The efficiency of the synthesis was also studied under various conditions, including reaction time (5, $30,60,90120,150$, and $180 \mathrm{~min})$, the $\mathrm{pH}(1,3,5,7$, $9,11)$, and temperature of the reaction $(5,20,30,40$, and $500 \mathrm{o})$. The reduction of silver ions to SNPs can be observed by the gradual change in the color of the solution. The final reaction solution was purified by centrifugation at $9000 \mathrm{rpm}$ for $30 \mathrm{~min}$. Supernatants were discarded, and the pellet was redispersed in deionized water to eliminate any contaminating plant materials before centrifuging twice at $9000 \mathrm{rpm}$ for 60 min. The pellet was dried at $37 \mathrm{oC}$ for $24 \mathrm{~h}$ to determine the dry mass of SNPs for further experiments.

\section{Characterization of SNPs}

The reduction of SNPs was confirmed using a UVVis spectrophotometer (Specord 200 plus-jena, Germany). The absorbance spectrum of the sample was obtained in the range of $400-700 \mathrm{~nm}$ wavelength, using a UV-Vis spectrometer with distilled water as a reference. The morphology of SNPs was determined with a JEOL JEM-1010, USA, operating at $100 \mathrm{kV}$. The
TEM grid was prepared by placing a drop of the bioreduced diluted solution on a carbon-coated copper grid and followed by drying it under a lamp.

\section{Effect of SNPs on vase life}

Experiments were conducted in the postharvest laboratory of Dalat University at $20 \pm 2{ }^{\circ} \mathrm{C}, 50 \pm 10 \%$ relative humidity under the daily $12 \mathrm{~h}$ photoperiod provided by 1100 lux fluorescent lights. The individual cut carnation stem was placed in the bottle containing $100 \mathrm{ml}$ of either water or water with SNPs or/and $2 \%$ sucrose. Mouths of the bottles were covered with non-absorption cotton to minimize evaporation loss and prevent contamination. The solution contains the following treatments and remains until the end of vase life: the treatments included: SNPs of 5, 15, 25, 35 ppm, SNPs of $5,15,25,35 \mathrm{ppm}+$ sucrose $2 \%$, alter (filtered through the membrane filter with the pore size of $0.2 \mu \mathrm{m}$ ) - the control, water (filtered through the membrane filter with the pore size of $0.2 \mu \mathrm{m})+$ sucrose $2 \%$. All experiments were carried out in triplicate.

Vase Life: Vase life was considered to have ended when visible of $30 \%$ petal color fading

Vase solution uptake: Average daily vase solution uptake was calculated in the vase containing $100 \mathrm{ml}$ of solution in 10 days by the formula ${ }^{19}$ :

$$
\operatorname{VSU}(\mathrm{g} / \mathrm{stem} / \text { day })=\sum_{1}^{10} \frac{\left(S_{t-1}-S_{t}\right)}{10 \times I F W}
$$

Where $S_{t}$ is the weight of vase of solution ( $g$ ) at $t$ day $=1,2,3, \ldots, S_{t-1}$ is the weight of vase of solution $(\mathrm{g})$ on the previous day, IFW is the initial fresh weight of stems.

Relative fresh weight: The relative freshwater (RFW) of cut flowers was calculated using the following formula: $\mathrm{RFW}(\%)=\left(\mathrm{FW}_{t} / \mathrm{FW}_{0}\right) \times 100$.

Where FWt is the fresh weight of stem $(\mathrm{g})$ at $\mathrm{t}=$ days $0,1,2$, etc., and $\mathrm{FW}_{0}$ is the fresh weight of stem $(\mathrm{g})$ at $\mathrm{t}=$ day 0 .

Flower diameter: The outer diameter of opened flowers was measured by a caliper in millimeters as an index for blossom expanding rate.

Bacterial counts: Bacterial solution populations were determined by spread the aliquots of vase solutions on nutrient agar and incubated at $30^{\circ} \mathrm{C}$ for 48 hours to count the total colony. Long stem-end segments of $2.5 \mathrm{~cm}$ were trimmed, washed with distilled water twice, and chopped into small pieces with sterile secateurs to investigate bacterial population in the stemend. These pieces were placed in the sterilized tube containing $1 \mathrm{ml}$ of sterile $0.9 \%$ saline and vortexed in 40 seconds. An aliquot of the extracts was spread 
onto nutrient agar plates. The plates were incubated at $30^{\circ} \mathrm{C}$ for 48 hours. For all tested samples, triplicate plate counts were made.

\section{Statistical analysis}

One-way analysis of variance (ANOVA) and t-test were performed using Excel 2011 statistical tools. A $\mathrm{P}$-value $<0.05$ was used as a criterion for the significance level. ANOVA was used to determine whether the bactericidal activity of SNPs and preservative ability from the different conditions (concentrations and with/without sucrose) are statistically different.

\section{RESULTS}

\section{Mechanism of SNPs synthesis}

The color of the solution changed from yellowish to dark brown (Figure 1). The color changes indicated that the bioreduction of silver ions to SNPs in the leaf extract of Prunus cerasoides. The formation of colloidal SNPs was monitored by measuring the UVVis spectrum that showed strong evidence of colloidal metal particle formation, and the productivity growth in the synthesis medium was indicated by the gradual increase in the absorbance values. Figure $2 \mathrm{a}$ shows the effect of heating duration at $60^{\circ} \mathrm{C}$ to prepare leaf extracts were optimized for biosynthesizing SNPs, including 5, 10, 15, 20, 25, and $30 \mathrm{~min}$ (Figure 2a). The absorption intensity demonstrated that the heat treatments at $60^{\circ} \mathrm{C}$ in $30 \mathrm{~min}$ yielded a larger amount of SNPs. The effect of $\mathrm{pH}$ conditions on the formation of nanoparticles was depicted in Figure $2 b$. The different reaction time was also characterized by biosynthesis (Figure 2c). All the spectra except for 5 and 30 min reaction had an intense peak $(436-437 \mathrm{~nm})$. As the concentrations of $\mathrm{AgNO}_{3}$ increasing from $1 \mathrm{mM}$ to $4 \mathrm{mM}$, a gradual increase in the absorption intensity was observed in Figure 2d. The optimum conditions for the synthesis of these SNPs from Prunus cerasoides leaf extracts are using the extract of leaf heating at $60^{\circ} \mathrm{C}$ in $30 \mathrm{~min}, 4 \mathrm{mM}$ of silver nitrate, $\mathrm{pH}$ of 11 , and $180 \mathrm{~min}$ of reaction time.

\section{Morphology of SNPs}

Scanning electron microscopy (SEM) was used to TEM image (Figure $3 \mathrm{a}$ ) visualized the size and morphology of the synthesized SNPs through leaf extracts of Prunus cerasoides under optimum conditions. SNPs predominated with spherical and oblong shape with size ranging from 5 to $70 \mathrm{~nm}$ with an average size of $43.15 \mathrm{~nm}$ (Figure 4 ). On the other hand, SEM image (Figure $3 \mathrm{~b}$ ) indicated that SNPs were spherical and oblong in shape and were in cluster, as well.

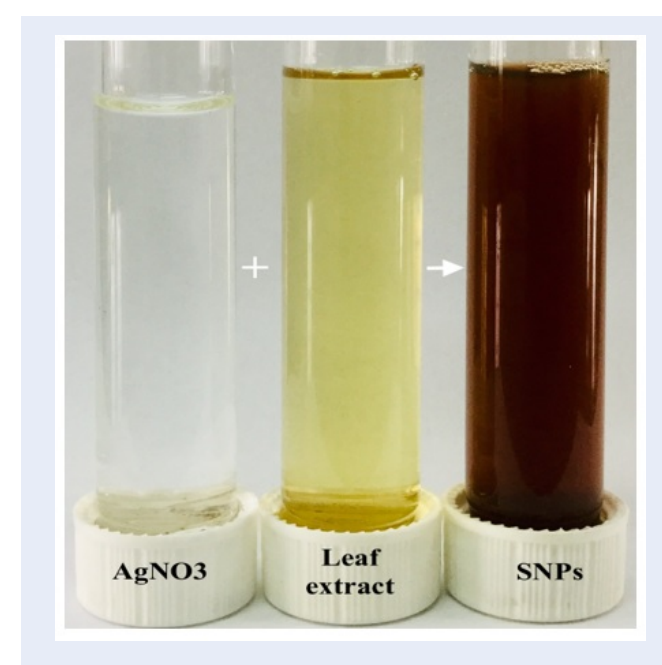

Figure 1: Procedure of SNPs green synthesis.

\section{Relative fresh weight and vase solution up- take}

The fresh weight (FW) increased every day in the first 3 days for all treatments and peaking between the $3^{\text {rd }}$ day to $7^{\text {th }}$ day (Figure 5). The FW of the control treatment remained until the 6th and started to decrease. All FW of other treatments remained above $100 \%$ till day 10. In treatments with SNPs without sucrose, the maximum fresh weight was observed in 25 ppm SNPs treatment at the 5 days and significantly greater than those in control. Sucrose alone and sucrose with SNPs had significant effects $(\mathrm{P}>0.05)$ on the relative fresh weight of cut carnation. The highest FW was obtained in the treatment by SNPs at 25ppm with $2 \%$ sucrose at the 7 day and remained almost constant in the rest days. In parallel with the FW, solution uptake in all treatments was significantly higher than the control (Figure 6). The maximum rate was shown in the treatment at $25 \mathrm{ppm}$ of SNPs with $2 \%$ sucrose. The solution uptake of cut carnation was significantly different between each SNPs concentration and the next higher concentration $(\mathrm{P}<0.05)$ in both combinations without and with sucrose.

\section{Vase life}

The vase life of cut carnation was prolonged under SNPs treatments with and without $2 \%$ sucrose (P

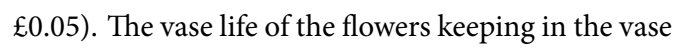
solution containing SNPs from 5, 15, 25, and $35 \mathrm{ppm}$ was terminated on day $13,4 \pm 0.3,14.4 \pm 0.1,15.2 \pm$ $0.3,13.8 \pm 0.2$, respectively, compared with $9 \pm 0.3$ days in the control (Figure 6). The increase of SNPs concentration from 5 to $25 \mathrm{ppm}$ extended the vase life. 




Figure 2: Effect of synthesis conditions on SNPs formation using UV-Vis spectroscopy measurement, (a) heating duration, (b) $\mathrm{pH}$, (c) reaction time, (d) concentrations of $\mathrm{AgNO}_{3}$.
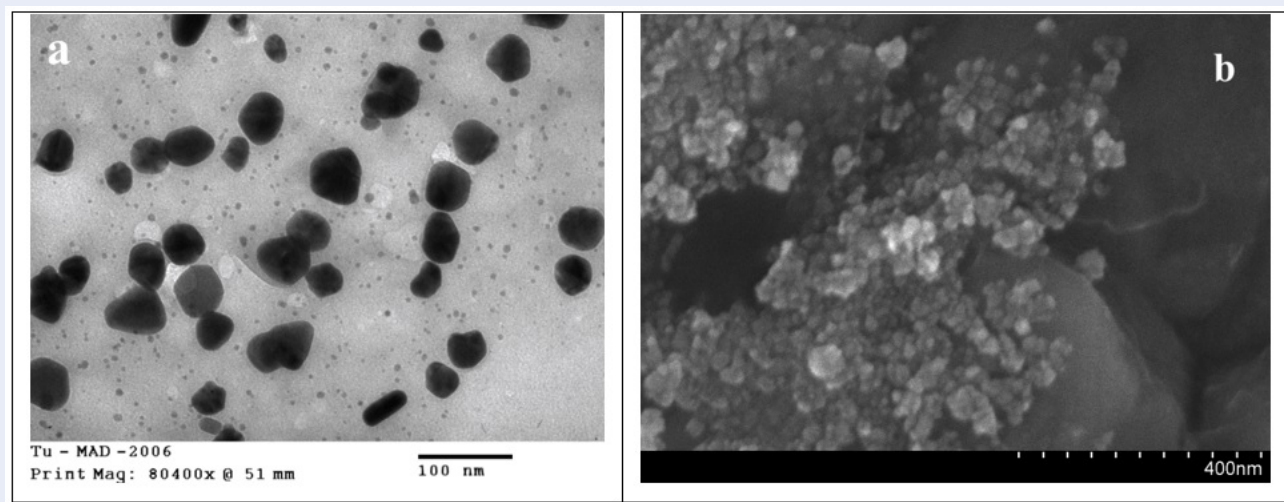

Figure 3: Morphology of SNPs: (a) TEM image; (b) SEM image.

However, the vase life was shorter in 35 ppm solution. Treatment with $2 \%$ sucrose in the solution promoted the longevity of cut carnation. The cut flowers' vase life has been shown to retard until $11 \pm 0.1$ days in the filtered water applied $2 \%$ sucrose. Keeping the cut carnation in the solution containing SNPs and $2 \%$ sucrose extended the vase life up to $19,8 \pm 0.3$ days, more twice the time comparing to the control (filtered water). A similar trend was observed in the treatment of $2 \%$ sucrose and $35 \mathrm{ppm}$ SNPs that the longevity of cut flowers decreased comparing to the treatment of $2 \%$ sucrose and 25 ppm SNPs (Figure 6).

\section{Flower diameter}

The effect of the SNPs on the flower diameter of the carnation cut flower was significant $(p \leq 0.05)$ as compared to the control (Figure 7). In the treatments without sucrose, the flower diameter of the control af- 


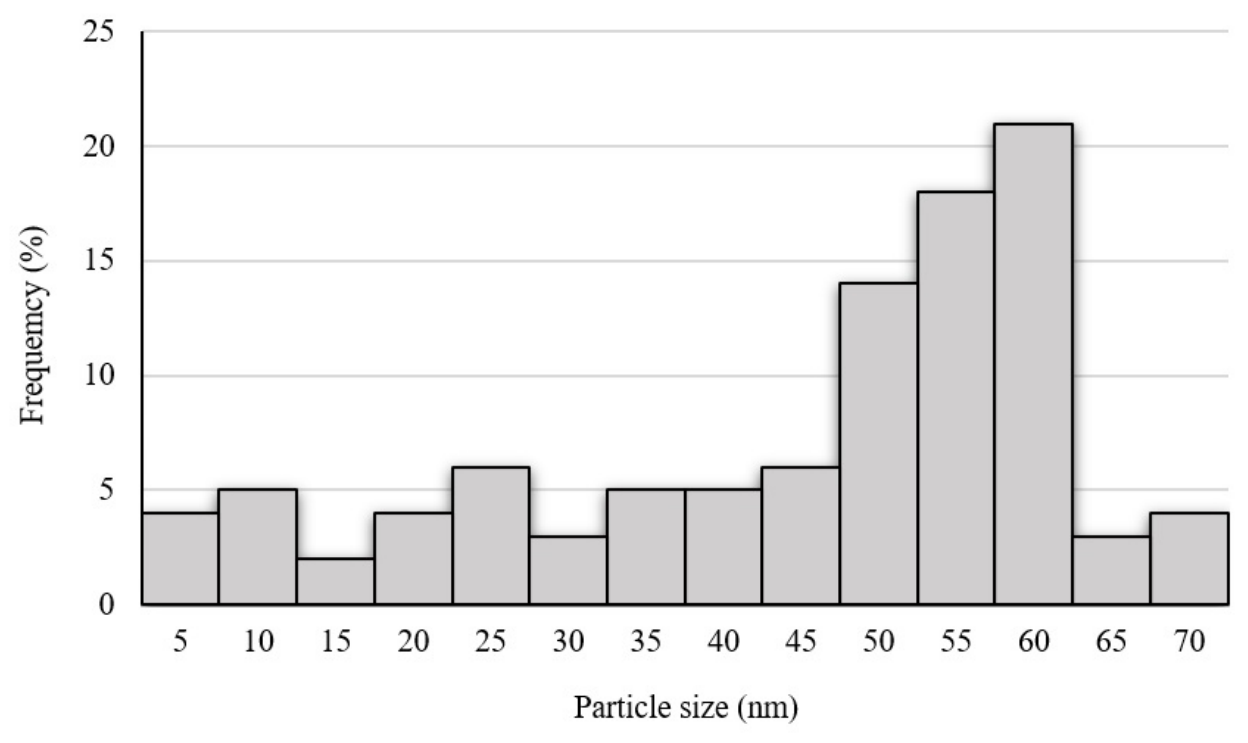

Figure 4: Particle size distribution histogram of bio-synthesized SNPs

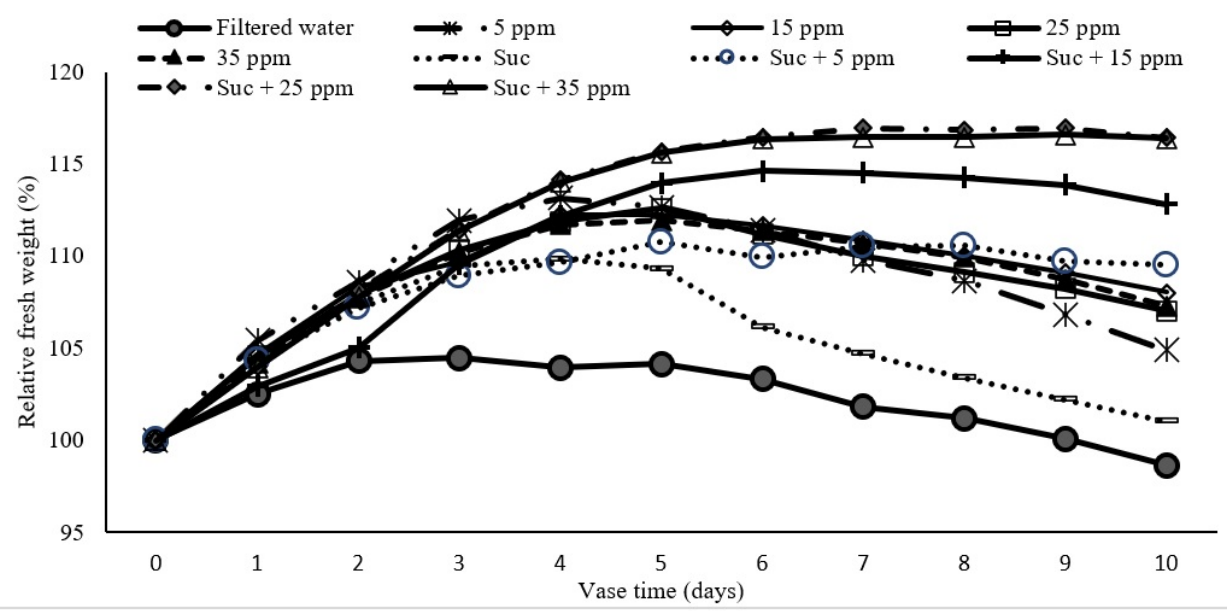

Figure 5: Relative fresh weight variation after 10 days of carnation vase life of the control (filtered water), the filtered water added SNPs $(5,15,25$, and 35 ppm), and the filtered water added SNPs $(5,15,25$, and 35 ppm) with $2 \%$ sucrose.

ter 10 days was 4 to $8 \mathrm{~cm}$ smaller than the SNPs treatments. It was observed that an increase in the SNPs concentrations from 5 to $25 \mathrm{ppm}$ led to an increase in the flower diameter. When the concentration of SNPs at $35 \mathrm{ppm}$, the diameter decreased compared with the previous lower concentration. SNPs could inhibit the bacteria development that interferes with water movement in the xylem. However, SNPs of 35 ppm could block the stem on their own as well.

\section{Bacterial counts}

The number of bacteria in the preservation solution and in the stem was measured after 10 days. Bacteria count number associated inversely with the vase life, relative fresh weight, vase solution uptake, and flower diameter (Figure 8). SNPs inhibited bacterial development in both stem and solution. In the solution with $2 \%$ sucrose without SNPs, $\log _{10}$ of bacteria was more than 10 compared to 9 in the filtrated water. The 


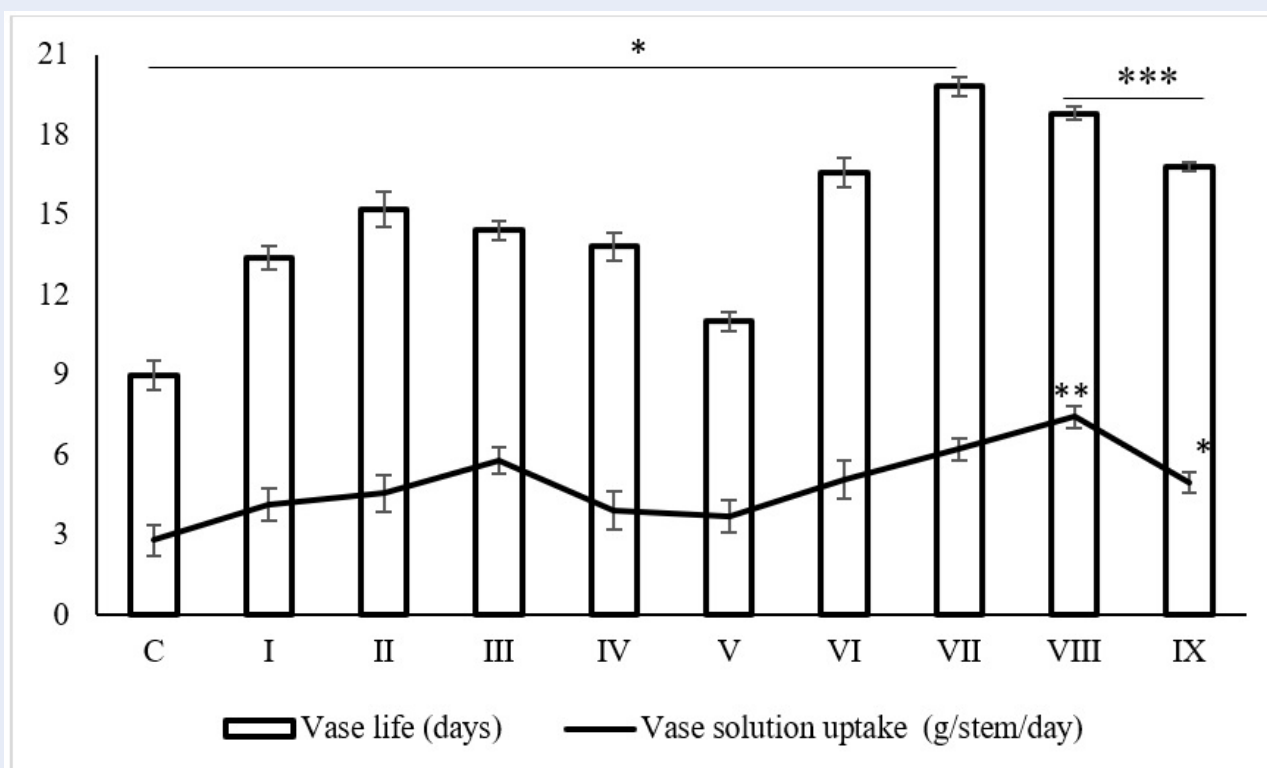

Figure 6: The effect of the different preservative solution on vase life and water uptake of carnation cut flowers: C: control (filtered water), I: 5 ppm SNPs, II: 15 ppm SNPs, III: 25 ppm SNPs, IV: 35 ppm SNPs, V: 2\% sucrose, VI: 5 ppm SNPs + 2\% Sucrose, VII: 15 ppm SNPs + 2\% Sucrose, VIII: 25 ppm SNPs + 2\% Sucrose, IX: 35 ppm SNPs + 2\% Sucrose. * indicates $\mathrm{P} \leq 0.05$; ${ }^{* *}$ indicates $\mathrm{P} \leq 0.01{ }^{* * *}$ indicates $\mathrm{P} \leq 0.001$.

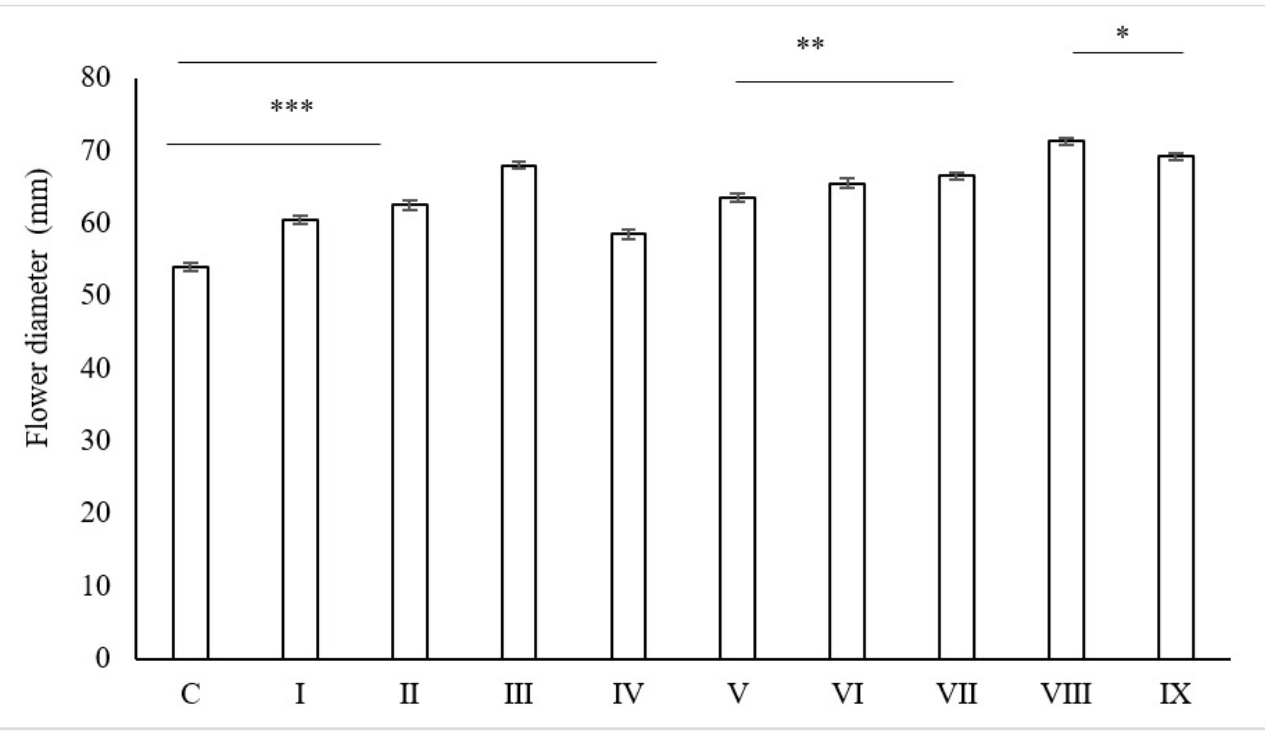

Figure 7: The effect of the different preservative solution on flower diameter of carnation cut flowers: C: control (filtered water), I: 5 ppm SNPs, II: 15 ppm SNPs, III: 25 ppm SNPs, IV: 35 ppm SNPs, V: $2 \%$ sucrose, VI: 5 ppm SNPs + 2\% Sucrose, VII: 15 ppm SNPs + 2\% Sucrose, VIII: 25 ppm SNPs + 2\% Sucrose, IX: 35 ppm SNPs + 2\% Sucrose. * indicates $\leq 0.05 ;{ }^{* *}$ indicates $\leq 0.01 ;{ }^{* * *}$ indicates $\leq 0.001$. 
number of bacteria in the solution added SNPs with and without sucrose dropped down dramatically. A similar trend was observed in the stem. The stems right after the harvest had a clear appearance (Figure 9). After 10 days, biofilm formation was in xylem vessels of the control and $2 \%$ sucrose treatment while xylem vessel obstructions were not observed clearly in the stems held in 25 ppm SNPs with and without $2 \%$ sucrose.

\section{DISCUSSION}

SNPs' formation was verified by the absorption ranging from 430 to $436 \mathrm{~nm}$, which is between typical surface plasmon resonance bands of metal nanoparticles with a size of less than $100 \mathrm{~nm}^{20}$. Heat duration time led to increased denaturation of capping agents, thereby influencing the nucleation of $\mathrm{Ag}^{+}$species and growth proficiency. Shifting $\mathrm{pH}$ from acidic to alkaline conditions was associated with the rise in absorption intensity, suggesting increasing SNPs' number was synthesis. Alkaline conditions enhance electron transfer in bio-reduction silver ions due to the conversation of phenolic groups to negatively charged phenolate ion ${ }^{21}$. The higher reduction of silver ions to nano form was enhanced with an increase in contacting time. It has been shown in Figure $2 \mathrm{~d}$ that SNPs formation was strongly influenced by metal ion concentration. The intensity of the plasmon peak increased with the increasing concentration of SNPs ${ }^{7}$. The increase in ion concentrations may induce a reaction of the substrate and $\mathrm{Ag}^{+}$species and then enhance the SNPs formation. Round and oblong shape SNPs were observed by TEM and SEM images. The availability of different quantities and types of capping agents in the leaf extract may lead to the variation in SNPs' size and distinctive shape.

SNPs had a significant effect on bacteria in the stem of carnations cut flowers. Vascular occlusion was induced by bacteria and their decay product in vase water and then shortened the vase life ${ }^{22}$. Bacteria may accelerate secrete pectic enzymes, toxic compounds, or ethylene, thereby prolonging the quality of cut flowers $^{22}$. It was assumed that SNPs inhibited microorganism contamination and then promoted the vase life relative to fresh weight, vase solution uptake, and flower diameter.

The short vase life of cut flowers is associated with many reasons. One is the low water transporting in stems due to the stem blockage. Many studies indicated that vascular blockage of the cut flower is due to microorganism development. Therefore, the exiting of antibacterial materials may enhance the positive effect on the cut flowers. At the concentrations of tested, SNPs had the effect on the carnation cut flowers in terms of relative fresh weight, vase solution uptake, vase life, flower diameter, and a number of bacteria in stem and preservative solution. SNPs inhibited the bacterial development and then alleviated the clogging stems. Thereby, water could be transport from the basal end up to leave and flowers. The high solution uptake during storage and the clean vascular stem could lead to the increment of the fresh weight in the initial period ${ }^{23,24}$.

The microbial contamination led to unable to uptake water because of the xylem tubes clogging. That could be the reason for ending vase life ${ }^{25}$. SNPs, an antibacterial agent, could inhibit the microbial development, keep the xylem clear, increase the water uptake, and then enhance the fresh weight and vase life. The data also indicated that flower diameter also improved in the treatment with SNPs. However, at the treatments of 35 ppm SNPs, the vase life decreased. The higher concentration of SNPs may block the vascular system and inhibit water transportation in the stems by themselves.

Sucrose, one carbohydrate, plays an important role in respiration, cell wall synthesis, and water balance maintaining ${ }^{26}$. SNPs inhibited the antibacterial and therefore supported the metabolic activity of sucrose. SNPs exhibited antibacterial activity while sucrose sustained the metabolic activity of cut flowers. Vase life can be shortened by lowering the carbohydrate levels in stems. Sucrose is one sugar that can transport to the flower buds and prolong the vase life. Sucrose provides energy regulates osmotic ${ }^{26}$; therefore, this carbohydrate influences the flower vase life. A solution containing SNPs plus sucrose significantly promoted the vase life because of increasing hydraulic conductance related to the high leaf water content ${ }^{27}$. Additionally, sucrose effectively increased the flower diameter on cut carnations compared to the treatments without sucrose.

It has been proved that $P$ runus cerasoides leaf extract can be used to synthesize SNPs. The green SNPs have a potential role in inhibiting bacteria in vase solution. Many chemicals are used to prolong the vase life of cut flowers, but most of these chemicals don't exhibit antibacterial activity clearly. In addition, SNPs combined with sucrose improved the quality of cut flowers. An energy source - sucrose and regulation of water - SNPs probably contributed to this effect. As far as we know, this is the first time the green synthesized SNPs from Prunus cerasoides leaf extract could be applied as an antibacterial agent in vase water to enhance the quality of cut carnation flowers. This suggests that 


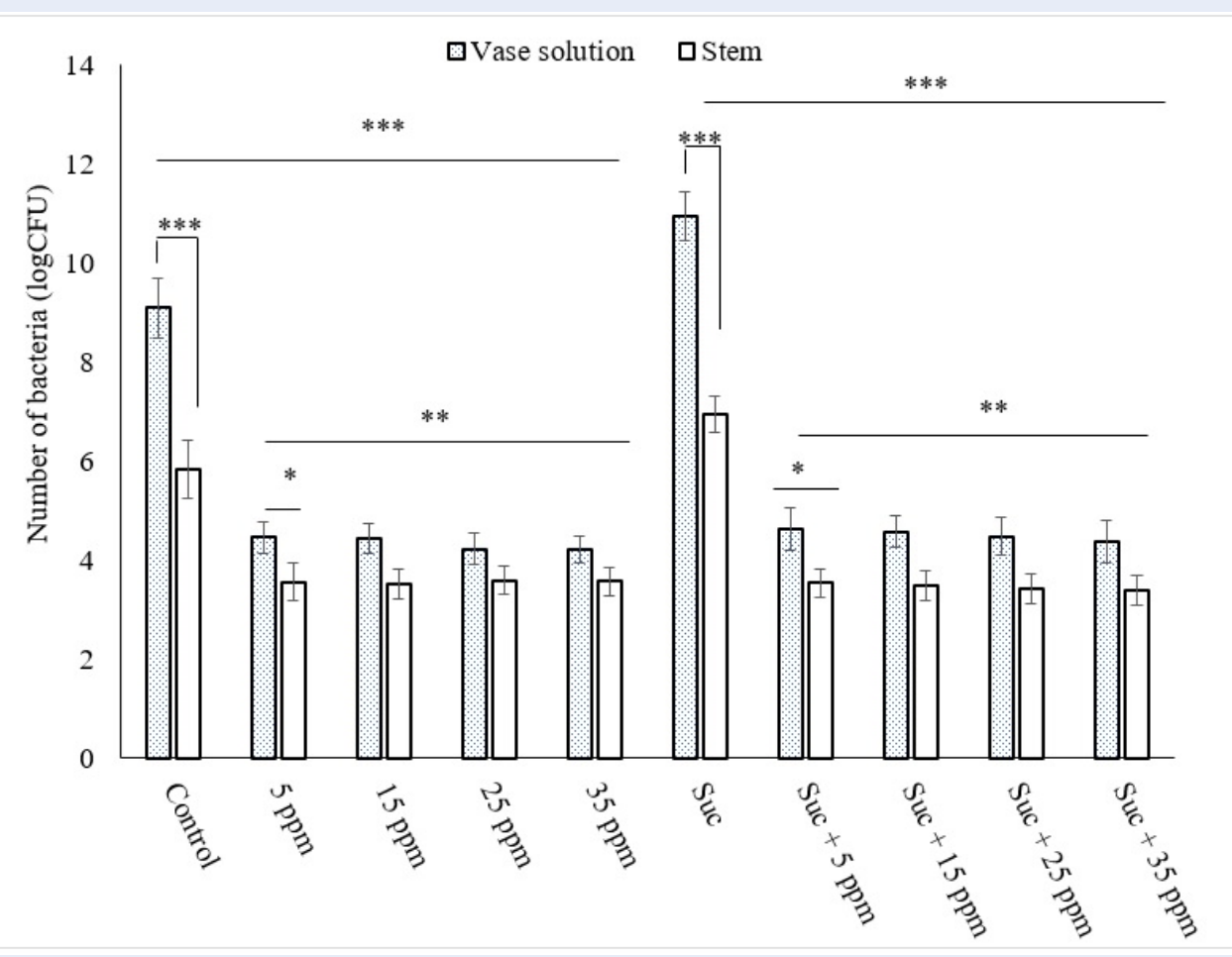

Figure 8: Changes in number of bacteria after 10 days in the stem end and vase solutions: ${ }^{*}$ indicates $\leq 0.05$; $* *$ indicates $\leq 0.01 ; * * *$ indicates $\leq 0.001$.

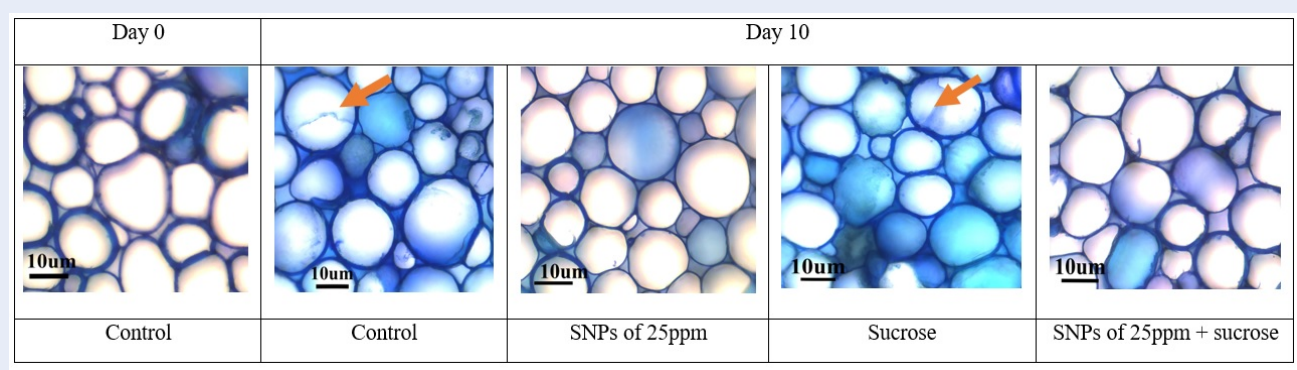

Figure 9: Morphology of the cut flower stem surface of carnation: red arrows show the biofilm in the vascular system.

a combination of sucrose and SNPs promises postharvest technology in promoting the quality of carnation cut flowers.

\section{CONCLUSIONS}

In conclusion, a rapid procedure for the biosynthesis of SNPs using leaf extract of Prunus cerasoides was established. Nanoparticles were characterized by UVVis, SEM, and TEM. The size of SNPs was 5 to 70 $\mathrm{nm}$ with spherical and oblong in shape. Vase solution containing SNPs inhibited the growth of bacteria and vascular clogging, then enhanced the vase life and de- layed senescence. This study also showed that $2 \%$ sucrose in holding solution prolonged the vase life and the bacterial development as well. Using the combination of SNPs and 2\% sucrose in the solution extended the vase life, relative fresh weight, vase solution uptake, flower diameter, and restrained bacteria from thriving. The best effect was observed at the combination of 25 ppm SNPs and 2\% sucrose. These results suggested that SNPs can be used as a promising antibacterial agent to take full advantage of sucrose in a preservative solution for carnation cut flowers. 


\section{LIST OF ABBREVIATIONS}

IFW: Initial fresh weight

RFW: Relative fresh water

SEM: Scanning electron microscopy

SNPs: Silver nanoparticles

TEM: Transmission electron microscopy

Uv-Vis: Ultraviolet-visible

VSU: Vase solution uptake

\section{COMPETING INTERESTS}

The authors commit that they have no competing interests.

\section{ACKNOWLEDGEMENTS}

This research is supported by Dalat University under the project code number: DLU2019-10.

\section{REFERENCES}

1. Jürgens $A$, Witt $T$, Gottsberger G. Flower scent composition in Dianthus and Saponaria species (Caryophyllaceae) and its relevance for pollination biology and taxonomy. Biochem Syst Ecol. 2003;31(4):345-357. Available from: https://doi.org/10. 1016/S0305-1978(02)00173-4.

2. Hashemabadi D. The role of silver nanoparticles and silver thiosulfate on the longevity of cut carnation (dianthus caryophyllus) flowers. J Environ Biol. 2014;35(4):661-666.

3. Salmond GPC. Secretion of extracellular virulence factors by plant pathogenic bacteria. Annu Rev Phytopathol. 1994;32:181-200. Available from: https: //doi.org/10.1146/annurev.py.32.090194.001145.

4. Monica JC, Heintz ME, Lewis PT. The perils of pre-emptive regulation. Nat Nanotechnol. 2007;2:68-70. PMID: 18654214 Available from: https://doi.org/10.1038/nnano.2007.15.

5. Birla SS, Gaikwad SC, Gade AK, Rai MK. Rapid Synthesis of Silver Nanoparticles from Fusarium oxysporum by Optimizing Physicocultural Conditions. Sci World J. 2013;2013:1-13. PMID: 24222751. Available from: https://doi.org/10.1155/ 2013/796018.

6. Rai M, Yadav A, Gade A. Silver nanoparticles as a new generation of antimicrobials. Biotechnol Adv. 2009;27(1):76-83. PMID: 18854209. Available from: https://doi.org/10.1016/j. biotechadv.2008.09.002

7. Dakal TC, Kumar A, Majumdar RS, Yadav V. Mechanistic basis of antimicrobial actions of silver nanoparticles. Front Microbiol. 2016;p. 1-17. PMID: 27899918. Available from: https://doi.org/ 10.3389/fmicb.2016.01831.

8. Xia QH, Zheng LP, Zhao PF, Wang JW. Biosynthesis of silver nanoparticles using Artemisia annua callus for inhibiting stem-end bacteria in cut carnation flowers. IET Nanobiotechnology. 2017;11(2):185-192. PMID: 28477002. Available from: https://doi.org/10.1049/iet-nbt.2015.0125.

9. Prasad TNVKV, Elumalai EK. Biofabrication of Ag nanoparticles using Moringa oleifera leaf extract and their antimicrobial activity. Asian Pac J Trop Biomed. 2011;1(6):439-442. Available from: https://doi.org/10.1016/S2221-1691(11)60096-8.

10. Saravanan M, Nanda A. Extracellular synthesis of silver bionanoparticles from Aspergillus clavatus and its antimicrobial activity against MRSA and MRSE. Colloids Surfaces B Biointerfaces. 2010;77(2):214-218. PMID: 20189360. Available from: https://doi.org/10.1016/j.colsurfb.2010.01.026.

11. Philip D, Unni C. Extracellular biosynthesis of gold and silver nanoparticles using Krishna tulsi (Ocimum sanctum) leaf. Phys E Low-Dimensional Syst Nanostructures. 2011;43(7):13181322. Available from: https://doi.org/10.1016/j.physe.2010.10. 006.
12. Sundeep D, Vijaya Kumar T, Rao PSS, Ravikumar RVSSN, Gopala Krishna A. Green synthesis and characterization of Ag nanoparticles from Mangifera indica leaves for dental restoration and antibacterial applications. Prog Biomater. 2017;6:5766. PMID: 28470622. Available from: https://doi.org/10.1007/ s40204-017-0067-9.

13. Maruti KKC, Yugandhar P, Suhrulatha D, Savithramma N. Synthesis, characterization and antimicrobial studies of stem bark mediated synthesis of silver nanoparticles from Adansonia digitata (L.). J Pharm Sci Res. 2015;7(2):76-82.

14. Park Y, Hong YN, Weyers A, Kim YS, Linhardt RJ. Polysaccharides and phytochemicals: A natural reservoir for the green synthesis of gold and silver nanoparticles. IET Nanobiotechnology. 2011;5(3):69-78. PMID: 21913788. Available from: https://doi.org/10.1049/iet-nbt.2010.0033.

15. Joseph N, Anjum N, Tripathi YC. Prunus cerasoides D. Don: A review on its ethnomedicinal uses, phytochemistry and pharmacology. Int J Pharm Sci Rev Res. 2018;48(1):62-69.

16. Arora DS, Mahajan H. Major Phytoconstituents of Prunus cerasoides Responsible for Antimicrobial and Antibiofilm Potential Against Some Reference Strains of Pathogenic Bacteria and Clinical Isolates of MRSA. Appl Biochem Biotechnol. 2019;188(4):1185-1204. PMID: 30854606. Available from: https://doi.org/10.1007/s12010-019-02985-4.

17. Damunupola JW, Ratnayake K, Joyce DC, Irving DE. Characterisation of xylem conduits and their possible role in limiting the vase life of cut Acacia holosericea (Mimosaceae) foliage stems. Funct Plant Biol. 2011;38(7):614-623. PMID: 32480914. Available from: https://doi.org/10.1071/FP11068.

18. Annamalai J, Nallamuthu T. Green synthesis of silver nanoparticles: characterization and determination of antibacterial potency. Appl Nanosci. 2016;6:259-265. PMID: 26900538. Available from: https://doi.org/10.1007/s13204-015-0426-6.

19. Henglein A. Physicochemical properties of small metal particles in solution: "Microelectrode" reactions, chemisorption, composite metal particles, and the atom-to-metal transition. J Phys Chem. 1993;97(21):5457-5471. Available from: https: //doi.org/10.1021/j100123a004.

20. Hulkoti NI, Taranath TC. Biosynthesis of nanoparticles using microbes-A review. Colloids Surfaces B Biointerfaces. 2014;121:474-483. PMID: 25001188. Available from: https: //doi.org/10.1016/j.colsurfb.2014.05.027.

21. Hutchinson $M$, Chebet $D$, Emongor V. Effect of accel, sucrose and silver thiosulphate on the water relations and post harvest physiology of cut tuberose flowers. African Crop Sci J. 2004;11(4):279-287. Available from: https://doi.org/10.4314/ acsj.v11i4.27578.

22. Jowkar MM, Khalighi A, Kafi M, Hassanzadeh N. Evaluation of aluminum sulfate as vase solution biocide on postharvest microbial and physiological properties of "Cherry Brandy" rose. Acta Hortic. 2013;3(1012):1132-1144. Available from: https: //doi.org/10.17660/ActaHortic.2013.1012.83.

23. Gebremedhin $\mathrm{H}$. Influence of preservative solutions on vase life and postharvest characteristics of rose (Rosa hybrid) cut flowers. Int J Biotechnol Mol Biol Res. 2013;4(8):111-118. Available from: https://doi.org/10.5897/IJBMBR2013.0171.

24. Carrillo-López LM, Morgado-González A, Morgado-González A. Biosynthesized Silver Nanoparticles Used in Preservative Solutions for Chrysanthemum cv. Puma. J Nanomater. 2016;2016:1-10. Available from: v.

25. Ichimura K, Kishimoto M, Norikoshi R, Kawabata $Y$, Yamada $K$. Soluble carbohydrates and variation in vase-life of cut rose cultivars "Delilah" and "Sonia." J Hortic Sci Biotechnol. 2005;80(3):280-286. Available from: https://doi.org/10.1080/ 14620316.2005.11511930.

26. Hayat $S$, Amin NU, Khan MA, Soliman TMA, Nan M, Hayat $K$, Zhao L. Impact of silver thiosulfate and sucrose solution on the vase life of rose cut flower Cv. cardinal. Adv Environ Biol. 2012;6(5):1643-1649.

27. Hatami M, Hatamzadeh A, Ghasemnezhad M, Ghorbanpour $M$. The comparison of antimicrobial effects of silver nanoparticles (snp) and silver nitrate (agno 3 ) to extend the vase life 
Science \& Technology Development Journal, 23(4):823-832

of "red ribbon" cut rose flowers. Trakia J Sci. 2013;2:144-151. 